\title{
Impact of the age of Biomphalaria alexandrina snails on Schistosoma mansoni transmission: modulation of the genetic outcome and the internal defence system of the snail
}

\author{
Iman Fathy Abou-El-Naga', Hayam Abd El-Monem Sadaka', Eglal Ibrahim Amer', \\ Iman Hassan Diab², Safaa Ibrahim Abd El-Halim Khedr¹/+ \\ ${ }^{1}$ Alexandria University, Faculty of Medicine, Medical Parasitology Department, Alexandria, Egypt \\ ${ }^{2}$ Alexandria University, Faculty of Medicine, Medical Biochemistry and Molecular Biology Department, Alexandria, Egypt
}

\begin{abstract}
Of the approximately 34 identified Biomphalaria species, Biomphalaria alexandrina represents the intermediate host of Schistosoma mansoni in Egypt. Using parasitological and SOD1 enzyme assay, this study aimed to elucidate the impact of the age of $\mathrm{B}$. alexandrina snails on their genetic variability and internal defence against $\mathrm{S}$. mansoni infection. Susceptible and resistant snails were reared individually for self-reproduction; four subgroups of their progeny were used in experiment. The young susceptible subgroup showed the highest infection rate, the shortest pre-patent period, the highest total cercarial production, the highest mortality rate and the lowest SODI activity. Among the young and adult susceptible subgroups, $8 \%$ and $26 \%$ were found to be resistant, indicating the inheritance of resistance alleles from parents. The adult resistant subgroup, however, contained only resistant snails and showed the highest enzyme activity. The complex interaction between snail age, genetic background and internal defence resulted in great variability in compatibility patterns, with the highest significant difference between young susceptible and adult resistant snails. The results demonstrate that resistance alleles function to a greater degree in adults, with higher SODl activity and provide potential implications for Biomphalaria control. The identification of the most susceptible snail age enables determination of the best timing for applying molluscicides. Moreover, adult resistant snails could be beneficial in biological snail control.
\end{abstract}

Key words: Biomphalaria alexandrina - Schistosoma mansoni - age - genetics - internal defence system

Schistosomiasis is recognised as a major neglected tropical disease, second only to malaria in terms of its adverse socioeconomic and public health impact in tropical and subtropical third-world developing countries. The disease affects more than 249 million people worldwide, with more than $90 \%$ of those requiring treatment residing in Africa (Hotez et al. 2012, WHO 2014). Schistosomiasis has been termed a "silent pandemic" due to the misery caused and decreased productivity of affected individuals (Morgan et al. 2001, King et al. 2005).

The worldwide distribution of Schistosoma mansoni, which causes intestinal schistosomiasis, is promoted by the broad geographic range of susceptible species of its intermediate host: pulmonate freshwater snails of the genus Biomphalaria. These snails serve as obligatory hosts for the larval stage, which infects humans. Of the more than 34 identified species of Biomphalaria, Biomphalaria alexandrina represents the intermediate host of S. mansoni in Egypt (DeJong et al. 2001, Morgan et al. 2001, El Naga et al. 2011).

doi: 10.1590/0074-02760150016

+ Corresponding author: siak_1380@yahoo.com

Received 13 January 2015

Accepted 11 May 2015
Different snail-specific factors are critical in determining Biomphalaria susceptibility to $S$. mansoni (Negrão-Corrêa et al. 2007, El Naga et al. 2010). Within this context, Newton (1952) found that susceptibility of $B$. glabrata to $S$. mansoni infection is a hereditary character. Moreover, resistance of B. glabrata to $S$. mansoni infection was found to vary with age; it is controlled in juveniles by at least four genes, each with several alleles, whereas in adulthood, only a single dominant gene determines this trait (Richards 1977, Richards \& Shade, Richards et al. 1992, Spada et al. 2002, Ittiprasert et al. 2010). In Biomphalaria tenagophila, two dominant genes determine resistance (Rosa et al. 2005). Nevertheless, for $B$. alexandrina, little is known about the effect of age on genetic modulation and $S$. mansoni infection compatibility.

Another important factor determining the compatibility of Biomphalaria species to S. mansoni infection is the snail's internal defence system (IDS). Different IDS responses to invading $S$. mansoni give rise to different degrees of susceptibility (El Naga \& Radwan 2012). The Biomphalaria IDS is mainly composed of circulating haemocytes (Negrão-Corrêa et al. 2007), which can inflict significant damage to invading parasites by generating reactive oxygen species (ROS) through an oxidative respiratory burst. Once generated, the first ROS of the burst, superoxide anion $\left(\mathrm{O}_{2}\right)$, can be metabolised to hydrogen peroxide $\left(\mathrm{H}_{2} \mathrm{O}_{2}\right)$. The cytosolic enzyme $\mathrm{Cu} / \mathrm{Zn}$ superoxide dismutase (SOD1) is produced by the snail haemocytes. SOD1 is a ubiquitous metalloenzyme that catalyses the reduction of highly reactive $\mathrm{O}_{2}-$ to $\mathrm{H}_{2} \mathrm{O}_{2}$, a 
cytotoxic component that acts as a defence mechanism to combat the parasite inside the snail (Hahn et al. 2001, Bayne 2009, Loker et al. 2010). Various studies have demonstrated that the $\mathrm{H}_{2} \mathrm{O}_{2}$ produced by Biomphalaria snails kills $S$. mansoni through potential oxidative damage and hence affects the susceptibility of the snails (Mahmoud \& Rizk 2004, Bender et al. 2005). Although the cytosolic location of snail $\mathrm{Cu} / \mathrm{Zn}$-SOD seems inconsistent with the need to direct $\mathrm{H}_{2} \mathrm{O}_{2}$ against a large extracellular parasite, $\mathrm{H}_{2} \mathrm{O}_{2}$ is stable and can readily diffuse across cell membranes. This is in contrast to $\mathrm{O}_{2}$-, which does not readily cross biological membranes, as its reaction with SOD1 occurs in the compartment where it is generated (Goodall et al. 2004, Bender et al. 2007).

SOD1 enzyme activity can be quantitated by measuring its resulting product using enzyme assays (Todd \& Gomez 2001).

With the current interest in eliminating schistosomiasis, a considerable variety of control strategies have been proposed. Nevertheless, total elimination has not yet been achieved and new cases are continuously diagnosed. It is clear that breaking the life cycle of this parasite will decrease its transmission and this can be achieved by targeting its intermediate host snail. To realise this goal, novel intervention tools are needed (Steinmann et al. 2006, Knight et al. 2014).

In 1958, Hubendick summarised a control method involving the reduction of a susceptible snail population by introducing a population that is known to be genetically resistant to the parasite. This method was later applied by Coelho et al. (2004) and Marques et al. (2014). Recent advances in our understanding of the genetics of hostparasite interactions have increased the interest in directing resistance genes into susceptible vector populations to render them resistant or even to exhibit low susceptibility when challenged by the parasite. Of course, a better longterm solution would be to generate the field resistant vector populations or those that are less susceptible to infection, an ecologically safer way of breaking transmission cycles (Townson et al. 2005, Bonner et al. 2012).

Studying the physiological and biochemical criteria that modulate Biomphalaria susceptibility to S. manso$n i$ is pivotal to provide new insights into the control of the targeted mollusc. Indeed, studies concerning the genetic variability of Biomphalaria with different degrees of susceptibility to $S$. mansoni infection can add to the development of control strategies for schistosomiasis (Oliveira et al. 2010).

Within this context, the current work studied the impact of the age of $B$. alexandrina snails on alterations in their genetic outcome and internal defence. This was achieved by using different parasitological parameters and an SOD1 enzyme assay.

\section{MATERIALS AND METHODS}

Parasitological study - Laboratory breeding scheme for snails - The snails used in this study were originally obtained from water channels running in Alexandria Governorate (Egypt) and were maintained for two years in the Parasitology Department, Faculty of Medicine, Alexandria University, Egypt. The snails were housed in glass aquaria containing snail-conditioned water and were fed lettuce leaves, tetramine fish food and calcium carbonate, under suitable environmental laboratory conditions, using the method described by Eveland and Haseeb (2011).

Source and maintenance of the parasite - S. mansoni cercariae were originally harvested from shedding $B$. alexandrina snails naturally infected with an Egyptian strain of S. mansoni and collected from Alexandria water channels. Maintenance of the S. mansoni life cycle was conducted between our laboratory snails and Swiss strain albino mice (El Naga et al. 2010). Groups of 10 snails were placed in $200 \mathrm{~mL}$ beakers containing aged de-chlorinated tap water (DTW) under direct sunlight for $2 \mathrm{~h}$. Each cercarial suspension was carefully shaken to obtain an even mixture and the average number of cercariae per $\mathrm{mL}$ was estimated. Mice were infected with 100 cercariae/mouse using the paddling tail-immersion technique according to the method described by Dettman et al. (1989). All work with laboratory animals was conducted in accordance with the Egyptian National Animal Welfare Standards and was approved by the Ethical Committee of the Faculty of Medicine, Alexandria University. At seven weeks post-infection (p.i.), mice were sacrificed and their livers were used as a source of parasite eggs. The eggs were then exposed to light to stimulate miracidial release. The snails were exposed individually to eight-10 vigorously swimming freshly hatched miracidia under direct sunlight for 3-4 $\mathrm{h}$ and then were kept in the dark and maintained under previously described conditions (El Naga et al. 2010, Eveland \& Haseeb 2011, Mostafa \& El-Dafrawy 2011).

Selection of susceptible and resistant snail stocks - Separation of resistant and susceptible isolates was achieved according to Zanotti-Magalhães (1997). For the selection of resistant individuals, snails that remained uninfected after exposure to infection were isolated $\left(\mathrm{F}_{1}\right)$ and reared singly for self-reproduction. Their progeny were selected as the experimental resistant group. Susceptible individuals were selected by isolation of snail progeny that yielded high infection frequencies $\left(\mathrm{F}_{1}\right)$ and were then reared singly for self-reproduction; these progeny were selected as the experimental susceptible group (Zanotti-Magalhães et al. 1997).

Experimental design - Two groups $\left(\mathrm{F}_{2}\right)$ were used in our experiments: 400 susceptible snails (group I) and 400 resistant snails (group II). Each group was further subdivided equally into two subgroups: 200 young susceptible (subgroup Ia) and 200 young resistant (subgroup IIa) snails were infected at the age of two months (before egg laying was initiated), at the size of 3-4 $\mathrm{mm}$ in diameter. Another 200 adult susceptible (subgroup Ib) and 200 adult resistant (subgroup IIb) snails were infected at the age of four months (after egg laying was initiated), at the size of $8-10 \mathrm{~mm}$ in diameter. Afterwards, the infected snails of each subgroup were returned to separate plastic aquaria and kept in darkness.

Two weeks later, 100 snails from each experimental subgroup were subjected to enzyme assay testing. The other 100 snails in each subgroup were used for the de- 
termination of parasitological parameters, starting from the 28th day post-exposure, twice weekly for three weeks. The experimental design used is illustrated in Figs 1, 2.

Determination of susceptibility and resistance of individual snails of the four subgroups - At four weeks post-exposure to the parasite, the snails from each experimental subgroup were individually checked for cercarial shedding twice weekly, repeatedly for three weeks. The susceptible and nonshedding snails of each subgroup were separated and returned to different containers. On the first day of detecting cercariae, the susceptible snails in each subgroup were isolated individually in small transparent plastic containers, each in $100 \mathrm{~mL}$ of aged DTW, and were kept in darkness throughout the shedding period. Each of the containers contained only one susceptible snail and

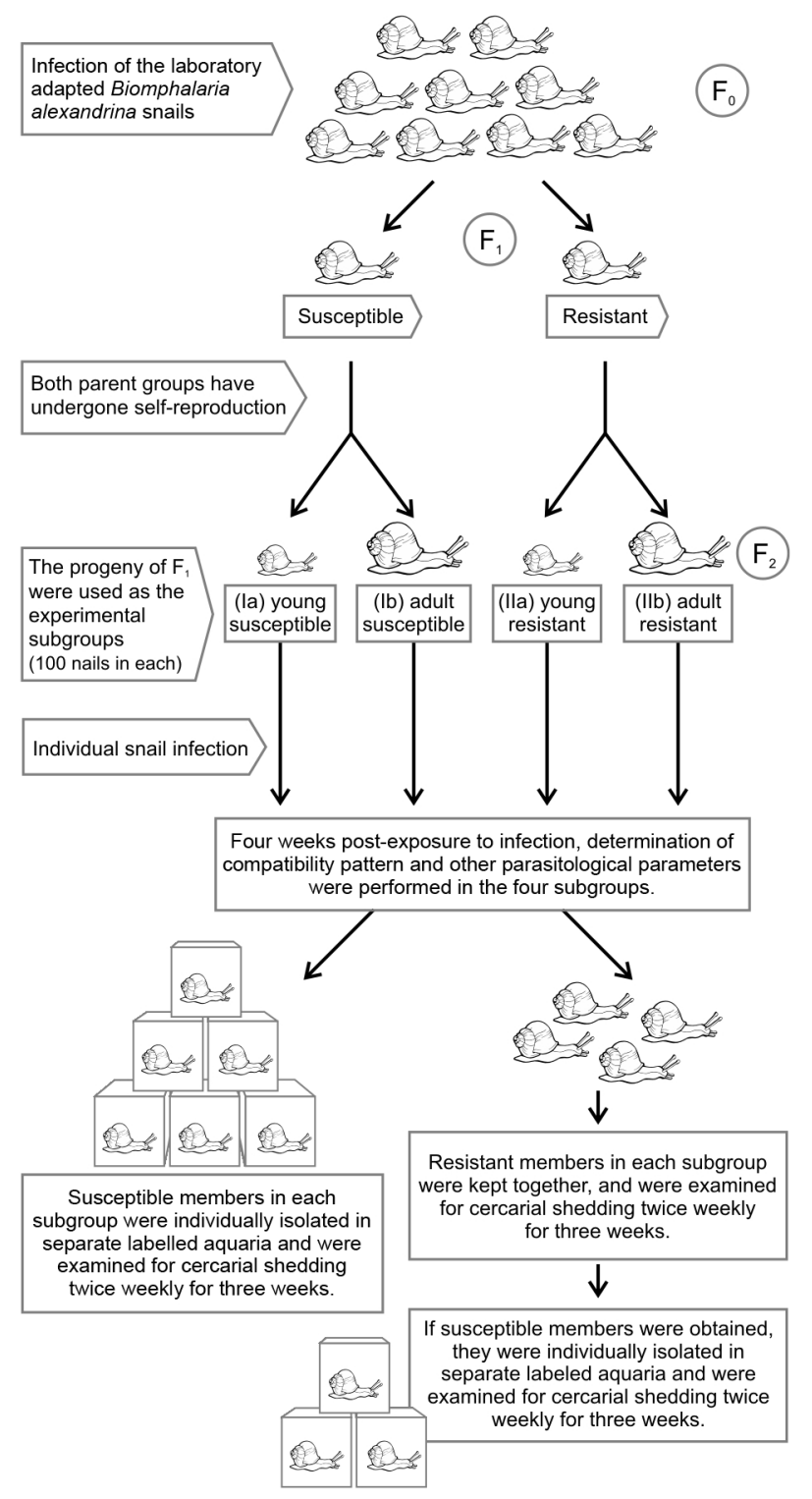

Fig. 1: a scheme showing the followed experimental design with regards to the parasitological parameters. was labelled with the experimental subgroup, the snail number, the pre-patent period (PPP) and the number of shed cercariae at each shedding assessment (ZanottiMagalhães et al. 1997, Yousif et al. 1998).

Nonshedding individuals from each subgroup were returned together into a separate aquarium and were tested twice weekly for cercarial shedding until the 49th day p.i. At the end of the three weeks dedicated to shedding, nonshedding snails were examined under the dissecting microscope to make sure there are no arrested developmental stages present. Moreover, if any snail died during the PPP, it was squeesed between two slides, entirely dissected and inspected under a stereo-dissecting microscope to detect developing sporocysts, which appear as opaque discrete masses within the snail tissue (Corrêa \& Paraense 1971, Niemann \& Lewis 1990).

Each shedding snail in all experimental subgroups was investigated for the following parasitological parameters.

$P P P$ - PPP is defined as the period from the day of snail exposure to miracidia to the day immediately before the first shedding of cercariae (Haroun 1996, Yousif et al. 1998). Starting from the 28th day post-exposure, all subgroups were examined twice weekly until the 49th day post-exposure; each snail was tested individually.

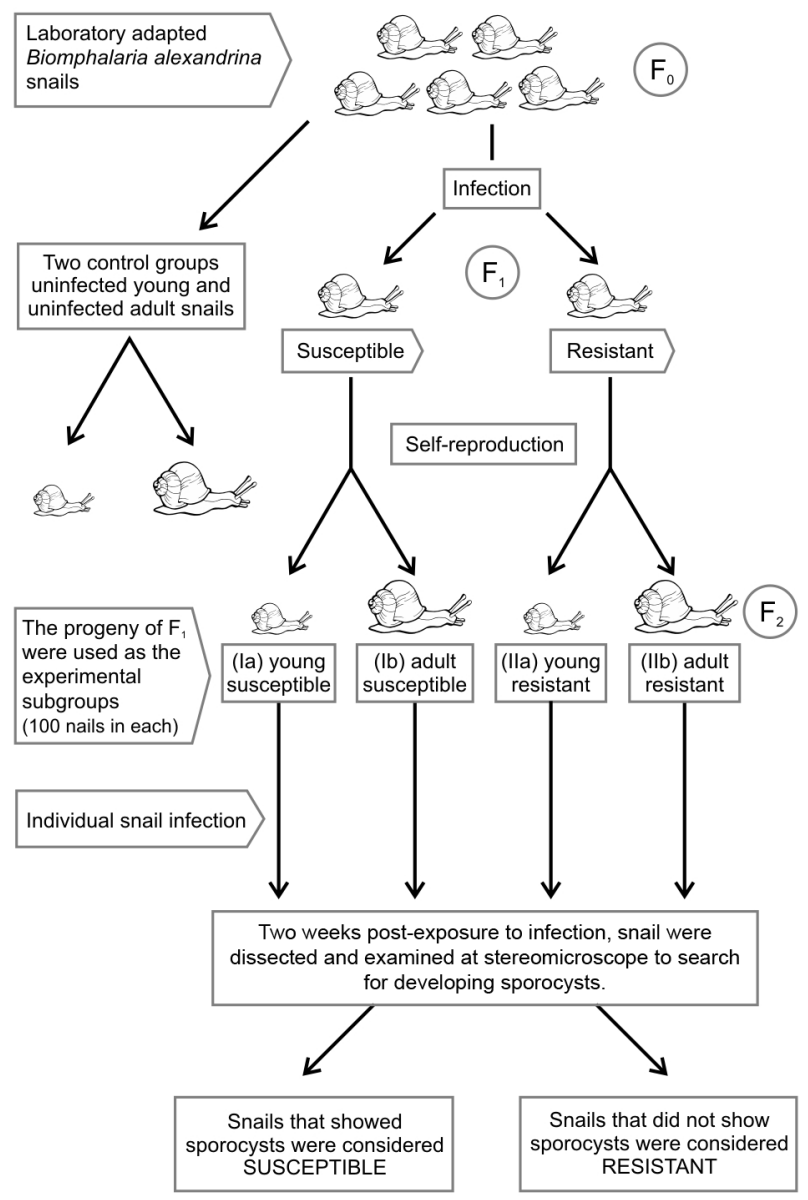

Fig. 2: a scheme showing the followed experimental design with regards to cytosolic superoxide dismutase enzyme assay. 
Infection rate (IR) - The snail IR was calculated by dividing the number of shedding and positive crushed snails by the number of exposed snails. The percentage of susceptible and resistant snails in each subgroup was then determined (Frandsen 1979, Yousif et al. 1998). The snail IR was calculated at the end of the experiment using the following equation:

$$
\text { IR } \%=\frac{\begin{array}{c}
\text { number of shedding and positive } \\
\text { crushed snails in each subgroup }
\end{array}}{\begin{array}{c}
\text { number of exposed snails } \\
\text { in each subgroup }
\end{array}} \times 100
$$

Mean cercarial output (MCO) - On the first day of cercariae detection, positive snails were separated individually and placed in plastic cups. The cercariae shed from each susceptible snail were counted under a stereomicroscope twice weekly for three successive weeks (Chu \& Dawood 1970, Frandsen 1979).

$$
\mathrm{MCO}=\frac{\begin{array}{c}
\text { sum of shed cercariae } \\
\text { at all shedding times }
\end{array}}{\text { number of shedding times }} \times 100
$$

Mortality rate $(M R)$ - The number of dead snails for each subgroup was counted starting from the day of exposure to the parasite until the 49 th day p.i. The number of dead snails in the breeding aquaria was recorded twice weekly. According to Yousif et al. (1998), the MR was calculated using the following equation:

$$
\begin{aligned}
& \text { the number of dead snails } \\
& \text { in each subgroup } \\
& \text { the total number of exposed } \\
& \text { snails in each subgroup }
\end{aligned}
$$

SOD1 enzyme assay - One hundred snails from each experimental subgroup were used for the enzyme assay. The assay was performed two weeks post-exposure to infection. Each snail was cleaned gently, dissected and examined under a stereomicroscope to detect developing sporocysts. Snails that did not show any sporocysts under the microscope were considered to be resistant.

Two control groups were used in the biochemical study: uninfected young snails and uninfected adult snails. Eight snails were included in each control group.

The soft tissue of the dissected snail was perfused with normal saline, blotted on tissue paper and weighed. The tissue was homogenised with phosphate-buffered saline ( $\mathrm{pH}$ 7.2) by sonication for $2 \mathrm{~min}$ in a glass test tube; to prevent temperature elevation to protect the enzymes present, the tube was placed in a beaker containing ice. The homogenised tissue was centrifuged at 500 $g$ for $4 \mathrm{~min}$ and the supernatant containing the proteins was stored in aliquots at $-20^{\circ} \mathrm{C}$ until use. This was repeated for each snail separately. The collected supernatants were used for an SOD1 enzyme assay.

The protein concentration for each homogenate supernatant was determined using Lowry's method (Sapan et al. 1999). The SOD1 activity was determined by adding the substrate of the enzyme to the snail tissue homo- genate and measuring the increase in absorbance over time during the reaction with a spectrophotometer according to Todd and Gomez (2001). A SOD1 enzyme assay kit, purchased from Biodiagnostic (Egypt), was used and relies on the ability of SOD1 to inhibit the phenazine methosulphate-mediated reduction of nitroblue tetrazolium. The kit was stored and prepared according to the manufacturer's instructions. Calculation:

percent inhibition $=\frac{\Delta \text { A control }-\Delta \text { A sample }}{\Delta \text { A control }} \times 100$

where $\Delta \mathrm{A}$ control $=$ the change in absorbance at $560 \mathrm{~nm}$ over 5 min following the addition of 5-methylphenazinium methyl sulfate (PMS) (R4) to the reaction mixture in the absence of the sample, $\Delta \mathrm{A}$ sample $=$ the change in absorbance at $560 \mathrm{~nm}$ over $5 \mathrm{~min}$ following the addition of PMS to the reaction mixture in the presence of the sample.

SOD1 activity: $\mathrm{U} / \mathrm{g}$ tissues used $=\%$ inhibition $\times 3.75 \times \frac{1}{\text { gram }} \times 100$

Statistical analysis - Data were analysed using the IBM SPSS software package v.20.0 (Kirkpatrick \& Feeney 2013). Qualitative data are described using a number and percent and quantitative data are described using the range (minimum and maximum), mean, standard deviation and median. Comparisons between the different studied subgroups were tested using the chi-square test. When more than $20 \%$ of the cells showed an expected count of less than 5, correction for chi-square was performed using Monte Carlo correction. The distributions of quantitative variables were tested for normality using the Kolmogorov-Smirnov test, the Shapiro-Wilk test and the D'Agstino test. Moreover, histogram and QQ plots were used for vision testing. When a normal data distribution was revealed, parametric tests were applied; if the data were abnormally distributed, nonparametric tests were used. For normally distributed data, comparisons between the different studied subgroups were analysed using the Ftest (ANOVA) and the post-hoc test (Scheffe) for pairwise comparisons. A significant test results are reported as two-tailed probabilities. The significance of the obtained results was judged at the 5\% level (Kotz et al. 2006).

Ethics - All work with laboratory animals was conducted in accordance with the Egyptian National Animal Welfare Standards and was approved by the Ethica Committee of the Faculty of Medicine, Alexandria University.

\section{RESULTS}

Parasitological study - PPP - Snails of each subgroup were individually examined for cercarial shedding twice weekly, starting from the 28th day after exposure to infection until the 49th day (Table I).

The maximum number of shedding snails on the 28th day among the four subgroups was observed in the young susceptible subgroup (Ia). Statistically significant differences were recorded between individuals of 
TABLE I

Number of shedding snails in each of the examined pre-patent period (PPP) days in the studied subgroups

\begin{tabular}{|c|c|c|c|c|c|c|}
\hline \multirow{2}{*}{$\begin{array}{l}\text { PPP } \\
(\mathrm{n}=100)\end{array}$} & \multicolumn{6}{|c|}{ Day } \\
\hline & 28 th & $32 \mathrm{nd}$ & 36 th & 40th & 44th & 49th \\
\hline Ia & 37 & 27 & 16 & 5 & 0 & 0 \\
\hline IIa & $2^{\mathrm{a}}$ & $3^{a}$ & $5^{a}$ & 7 & $9^{a}$ & $11^{a}$ \\
\hline $\mathrm{Ib}$ & $11^{a, b}$ & $14^{a, b}$ & $16^{b}$ & $17^{a, b}$ & $9^{a}$ & $7^{a}$ \\
\hline $\mathrm{IIb}$ & $0^{a, c}$ & $0^{a, c}$ & $0^{a, c}$ & $0^{b, c}$ & $0^{b, c}$ & $0^{b, c}$ \\
\hline$\chi^{2}$ & $79.451^{d}$ & $45.965^{d}$ & $23.200^{d}$ & $22.716^{d}$ & $18.848^{d}$ & $20.710^{d}$ \\
\hline $\mathrm{p}$ & $<0.001^{d}$ & $<0.001^{d}$ & $<0.001^{d}$ & $<0.001^{d}$ & ${ }^{\mathrm{MC}} \mathrm{p}<0.001^{d}$ & ${ }^{\mathrm{MC}} \mathrm{p}<0.001^{d}$ \\
\hline
\end{tabular}

$a$ : significance with subgroup Ia (young susceptible); $b$ : significance with subgroup IIa (young resistant); $c$ : significance with subgroup Ib (adult susceptible); $d$ : statistically significant at $\mathrm{p} \leq 0.05$; IIb: adult resistant subgroup; MC: Monte Carlo test; n: number of members in each subgroup; $\chi^{2}$ : value for chi-square test.

TABLE II

Infection rate (IR) among the studied subgroups

\begin{tabular}{|c|c|c|c|c|c|c|}
\hline & Ia & IIa & $\mathrm{Ib}$ & IIb & $\chi^{2}$ & $\mathrm{p}$ \\
\hline $\operatorname{IR}(\%)$ & 92 & 37 & 74 & 0 & $200.315^{a}$ & $<0.001^{a}$ \\
\hline Sig & \multicolumn{4}{|c|}{ 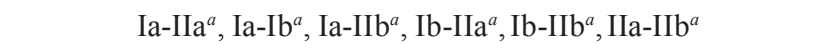 } & - & - \\
\hline
\end{tabular}

$a$ : statistically significant at $\mathrm{p} \leq 0.05$; Ia: young susceptible subgroup; Ib: adult susceptible subgroup; IIa: young resistant subgroup; IIb: adult resistant subgroup; Sig: significance between subgroups using chi-square test $\left(\chi^{2}\right)$.

TABLE III

Cercarial roduction in the studied subgroups

\begin{tabular}{lccc}
\hline \multicolumn{3}{c}{ Shedding snails } & \\
Subgroups & (n) & TCP & MCO \\
\hline Ia & 85 & 151,002 & $298.1 \pm 132.13$ \\
IIa & 37 & 9,877 & $44.49 \pm 32.35$ \\
Ib & 74 & 41,732 & $94.13 \pm 44.17$ \\
IIb & 0 & 0 & $0.0 \pm 0.0$ \\
\hline
\end{tabular}

Ia: young ceptible bgroup; Ib: adult ceptible bgroup; IIa: young resistant subgroup; IIb: adult resistant subgroup; MCO: mean cercarial output (mean number of cercariae/snail/shedding time); TCP: total number of cercariae/subgroup. Normally distributed data were expressed in mean \pm standard deviation.

the same group. These differences were demonstrated among the susceptible young (Ia) and susceptible adult (Ib) subgroups at all studied time points, except on the 36 th day. In contrast, there were no significant differences between the young resistant (IIa) and adult resistant (IIb) subgroups at the earlier time points. Significant differences were found at the 40th, 44th and 49th days.

Additionally, significant differences between the young subgroups Ia and IIa at all the time points, except on the 40th day, were also observed. Furthermore, significant differences were found between the susceptible and resistant adult subgroups ( $\mathrm{Ib}$ and $\mathrm{IIb}$ ) on all days of shedding.
$I R \%$ - The percentage of susceptible and resistant snails in each subgroup was determined. IRs were $92 \%$, $74 \%, 37 \%$ and $0 \%$ in the subgroups $\mathrm{Ia}, \mathrm{Ib}$, IIa and $\mathrm{IIb}$, respectively. Statistically significant differences among the susceptible and resistant groups at different snail ages and among young and adult subgroups with different compatibility patterns were evident (Table II).

Total cercarial production (TCP) and MCO per susceptible snail - The total number of cercariae produced by the susceptible snails in subgroups Ia, Ib and IIa was counted twice weekly over a period of three weeks. The mean number of cercariae shed by each susceptible snail in the different studied subgroups was calculated and is presented in Tables III, IV. The young susceptible subgroup (Ia) yielded the highest MCO, at 298.1 \pm 132.13 (Tables III, IV).

$M R \%$ - The number of dead snails for each subgroup was counted from the day of exposure to infection until the 49th day p.i. The MR for each subgroup was $47 \%$, $35 \%, 27 \%, 14 \%$ for subgroups Ia, Ib, IIa and IIb, respectively (Table V). A positive correlation between both infection and MRs of each subgroup was demonstrated, with mortality increasing with infection (Table VI).

Enzyme assay - The SOD1 enzyme activities in the noninfected (young and adult) subgroups were $0.26 \pm$ 0.04 and $0.30 \pm 0.03 \mathrm{U} / \mathrm{g}$ tissues, respectively. In the infected subgroups, the highest level of SOD1 enzyme activity was obtained in the adult resistant subgroup (IIb), with a mean of $0.90 \pm 0.07 \mathrm{U} / \mathrm{g}$ tissues, whereas the low- 
est enzyme activity was in the susceptible individuals of the young susceptible subgroup (Ia), at $0.32 \pm 0.03$. The enzyme activity was higher in the resistant snails, regardless of their age, in comparison to susceptible and noninfected snails. Furthermore, the SOD1 activity was higher in the adult subgroups than in the young subgroups (Table VII).

\section{DISCUSSION}

Infection of Biomphalaria species by the larval stage of $S$. mansoni leads to an intimate, long-term association that largely challenges the snail's physical integrity and severely compromises its biological fitness (Sandland et al. 2007). Although the infective stage (miracidia) is small relative to the host, once inside the host's body, miracidia initiate major developmental changes to support their extensive growth and transformation to more specialised larval stages (de Jong-Brink 1995). Based on a postulation

\section{TABLE IV}

Mean cercarial shedding over three successive weeks per susceptible snail among the studied subgroups

\begin{tabular}{lcccc}
\hline & Ia & IIa & Ib & IIb \\
\hline Min-Max & $97-594$ & $18-173$ & $20-214$ & $0-0$ \\
Mean \pm SD & $298.1 \pm 132.1$ & $44.5 \pm 32.35$ & $94.13 \pm 44.2$ & $0.0 \pm 0.0$ \\
Median & 271.0 & 33.50 & 90.50 & 0.0 \\
F test & \multicolumn{5}{c}{$234.333^{a}$} \\
p & $<0.001^{a}$
\end{tabular}

Sig

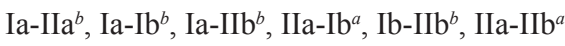

$a$ : statistically significant at $\mathrm{p} \leq 0.05 ; b$ : statistically significant at $\mathrm{p} \leq 0.001$; Ia: young susceptible subgroup; Ib: adult susceptible subgroup; IIa: young resistant subgroup; IIb: adult resistant subgroup; Sig: significant difference between subgroups using post-hoc test (Scheffe). Normally distributed data were expressed in mean \pm standard deviation (SD) and was compared using $\mathrm{F}$ test (ANOVA). of the short life span of miracidium in water, which at the same time gives rise to hundreds of cercariae, schistosome development inside its snail intermediate host can be considered the weakest link in the parasite's life cycle. Additionally, although a given parasite strain can only develop within a compatible snail, no such discrimination occurs in the human host. Therefore, snail control is highly effective in eliminating schistosomiasis and is also easier than changing human habits. For these reasons, searching for snail factors that prevent parasite development will help in designing tools that can be utilised for controlling schistosomiasis (Knight et al. 2014).

Genetic background and the IDS are snail-related factors that are known to affect the compatibility of Biomphalaria to S. mansoni (Richards 1975, NegrãoCorrêa et al. 2007). Age-dependent variability in susceptibility to $S$. mansoni has been studied in B. glabrata (Richards 1984, Spada et al. 2002, Ittiprasert et al. 2010) and it was found that the number of genes controlling resistance differs with the age of the snail, which in turn affects the compatibility pattern (Richards 1977, Richards et al. 1992). Moreover, the number of genes controlling resistance varies among Biomphalaria species (Richards 1977, Richards et al. 1992, Rosa et al. 2005), which highlights the importance of studying the effect of age on the genetic outcome of $B$. alexandrina.

Biomphalaria's IDS is the most important defence mechanism against S. mansoni infection. Haemocytes constitute a major IDS element. These cells produce the enzyme cytosolic SOD1, an important enzyme that catalyses the conversion of $\mathrm{O}_{2}$ - to $\mathrm{H}_{2} \mathrm{O}_{2}$. The $\mathrm{H}_{2} \mathrm{O}_{2}$ produced by Biomphalaria snails kills $S$. mansoni through its potential oxidative damage, thereby affecting snail susceptibility (Bender et al. 2007, Negrão-Corrêa et al. 2007).

Goodall et al. (2006) found that SOD1 enzyme expression in $B$. glabrata differs among susceptible and resistant snails. However, the effect of the snail's age on the activity of this enzyme has not been evaluated.

Within this context, the current work examined the effect of the age of $B$. alexandrina snails on their genetic outcome and on the activity of SOD1 (as a representa-

TABLE V

Mortality rate (MR) among the studied subgroups at the different studied pre-patent periods with compatibility status of the dead snails

\begin{tabular}{|c|c|c|c|c|c|c|}
\hline \multirow[b]{2}{*}{ MR (\%) } & \multicolumn{6}{|c|}{ Day } \\
\hline & 28th & $32 \mathrm{nd}$ & 36 th & 40th & 44th & 49th \\
\hline Ia (47) & $7(7 S)$ & 0 & $2(2 S)$ & $5(5 S)$ & $14(14 S)$ & 19 (19S) \\
\hline IIa (27) & $2(2 \mathrm{R})$ & $3(3 R)$ & $3(1 \mathrm{R}, 2 \mathrm{~S})$ & $5(2 \mathrm{R}, 3 \mathrm{~S})$ & $6(2 \mathrm{R}, 4 \mathrm{~S})$ & $8^{a}(4 \mathrm{R}, 4 \mathrm{~S})$ \\
\hline $\mathrm{Ib}(35)$ & $0^{a}$ & 0 & $3(3 \mathrm{~S})$ & $6(6 S)$ & $11(10 \mathrm{~S}, 1 \mathrm{R})$ & $15(13 \mathrm{~S}, 2 \mathrm{R})$ \\
\hline IIb (14) & $1(1 \mathrm{R})$ & $1(1 \mathrm{R})$ & $2(2 \mathrm{R})$ & $3(3 R)$ & $3^{a, b}(3 \mathrm{R})$ & $4^{a, b}(4 \mathrm{R})$ \\
\hline$\chi^{2}$ & $27.085^{c}$ & $11.897^{c}$ & 0.410 & 1.05 & $9.368^{c}$ & $13.461^{c}$ \\
\hline $\mathrm{P}$ & $<0.001^{c}$ & ${ }^{\mathrm{MC}} \mathrm{p}=0.015^{c}$ & ${ }^{\mathrm{MC}} \mathrm{p}=1.000$ & ${ }^{\mathrm{MC}} \mathrm{p}=0.874$ & $0.025^{c}$ & $0.004^{c}$ \\
\hline
\end{tabular}

$a$ : significance with subgroup Ia (young susceptible); $b$ : significance with subgroup Ib (adult susceptible); $c$ : statistically significant at $\mathrm{p} \leq 0.05$; IIa: young resistant subgroup; IIb: adult resistant subgroup; MC: Monte Carlo test; R: resistant; S: susceptible; $\chi^{2}$ : value for chi-square test. 
tive of IDS). The present work was conducted using approaches involving both parasitological and biochemical techniques and was achieved by including 200 snails in each of four experimental subgroups: young susceptible (Ia), adult susceptible (Ib), young resistant (IIa) and adult resistant (IIb). In each subgroup, 100 snails were dedicated for parasitological examination that began four weeks post-exposure to miracidia and continued for the following three weeks. The other 100 snails were used for the biochemical study (SOD1 enzyme assay), which was performed at two weeks post-exposure to infection.

We investigated the effect of the age of snails on their compatibility pattern. Moreover, the effect of the interaction of snail age, genetics and internal defence on the outcome of infection was also examined.

Our results revealed that younger snails, belonging to either a susceptible or resistant group, showed higher susceptibility when compared to adult snails. Young sus-

\section{TABLE VI}

Correlation between infection rate (IR) and mortality rates (MR) in the studied subgroups

\begin{tabular}{lccc}
\hline Correlation & $\begin{array}{l}\text { IR } \\
(\%)\end{array}$ & $\begin{array}{l}\text { MR } \\
(\%)\end{array}$ & $\mathrm{p}$ \\
\hline $\mathrm{Ia}$ & 92 & 47 & $<0.001^{a}$ \\
$\mathrm{IIa}$ & 37 & 27 & 0.130 \\
$\mathrm{Ib}$ & 74 & 35 & $<0.001^{a}$ \\
$\mathrm{IIb}$ & 0 & 14 & $<0.001^{a}$ \\
$\mathrm{r}(\mathrm{p})$ & $0.983\left(0.017^{a}\right)$ & -
\end{tabular}

$a$ : statistically significant at $\mathrm{p} \leq 0.05$; Ia: young susceptible subgroup; Ib: adult susceptible subgroup; IIa: young resistant subgroup; IIb: adult resistant subgroup; p: p-value for chi-square test; r: Pearson coefficient. ceptible snails exhibited the shortest range of PPP, with the majority of shedding snails being recorded by the 28 th day, at 37 of 85 shedding snails. Moreover, the remainder of shedding snails in the same subgroup showed their first shedding before the 40th day p.i.: 27 snails shed cercariae for the first time on the 32nd day, 16 snails shed on the 36th day and five snails shed on the 40th day.

Regarding the adult susceptible subgroup (Ib), of 74 shedding snails, only 11 shed for the first time on the 28th day p.i. The maximum number of shedding snails was 16 and 17 recorded by the 36th and the 40th days, respectively. Additionally, PPP extended to the 49th day in seven snails.

Njiokou et al. (2004) and El Naga et al. (2011) stated that high snail compatibility to trematode infection is characterised by a short PPP. The significant differences observed between subgroups $\mathrm{Ia}$ and $\mathrm{Ib}$ with regard to shedding durations indicate that subgroup Ia (young susceptible) carries higher susceptibility to $S$. mansoni infection, accompanied by rapid development of the parasite inside the snail.

As for subgroup IIa (young resistant) shedding members, the maximum number of shedding snails for the first time was 11 that were recorded by the 49th day with only two snails shed for the first time by the 28th day. Conversely, the snails belonging to the adult resistant subgroup IIb displayed only the resistant phenotype, with no recoded PPP. Subgroup IIa (young resistant) showed a significant difference compared to subgroup IIb (adult resistant), which contained only resistant individuals, indicating higher susceptibility of the former. These significant differences between subgroups Ia and $\mathrm{Ib}$ and between IIa and IIb can be attributed to the effect of age.

It was not surprising that the compatibility pattern also affected the outcome of infection, as evidenced by the significant differences between subgroups Ia and IIa

TABLE VII

The level of cytosolic superoxide dismutase enzyme (SOD1) per snail's gram tissue in U/g tissues among the studied subgroups

\begin{tabular}{lccccccccc}
\hline $\begin{array}{l}\text { SOD } 1 \\
(\mathrm{U} / \mathrm{g})\end{array}$ & $\mathrm{Ca}$ & $\mathrm{Cb}$ & $\mathrm{Ia} \mathrm{s}$ & Ia r & Ila s & IIa r & Ib s & Ib r & IIb \\
\hline Min-Max & $0.20-0.31$ & $0.25-0.35$ & $0.25-0.35$ & $0.43-0.63$ & $0.34-0.45$ & $0.66-0.83$ & $0.21-0.44$ & $0.61-0.73$ & $0.79-0.99$ \\
Mean \pm SD & $0.26 \pm 0.04$ & $0.30 \pm 0.03$ & $0.32 \pm 0.03$ & $0.55 \pm 0.07$ & $0.40 \pm 0.03$ & $0.76 \pm 0.05$ & $0.34 \pm 0.07$ & $0.68 \pm 0.04$ & $0.90 \pm 0.07$ \\
Median & 0.26 & 0.30 & 0.32 & 0.58 & 0.40 & 0.77 & 0.36 & 0.67 & 0.91 \\
F & - & - & - & - & $209.018^{a}$ & - & - & - & - \\
p & - & - & - & - & $<0.001^{a}$ & - & - & - & - \\
Sig & - & - & - & $b-d$ & $b, c, e$ & $b-f$ & $e, g$ & $b-f, h$ & $b-i$ \\
\hline
\end{tabular}

$a$ : statistically significant at $\mathrm{p} \leq 0.05 ; b$ : significance with group uninfected young; $c$ : significance with group uninfected adult; $\mathrm{d}$ : significance with subgroup Ia (young susceptible members); $e$ : significance with subgroup Ia (young resistant members); $f$ : significance with subgroup IIa (young susceptible members); $g$ : significance with subgroup IIa (young resistant members); $h$ : significance with subgroup Ib (adult susceptible members); $i$ : significance with subgroup Ib (adult resistant members); Ca: young noninfected; $\mathrm{Cb}$ : adult noninfected; Ia r: young susceptible subgroup (resistant members); Ia s: young susceptible subgroup (susceptible members); Ib r: adult susceptible subgroup (resistant members); Ib s: adult susceptible subgroup (susceptible members); IIa r: young resistant subgroup (resistant members); IIa s: young resistant subgroup (susceptible members); Sig: significance between subgroups was done using post-hoc test (Scheffe). Normally distributed data were expressed in mean \pm standard deviation (SD) and was compared using $\mathrm{F}$ test (ANOVA). 
and between subgroups Ib and IIb. Moreover, the significant differences recorded between young resistant, susceptible snails and adult susceptible, susceptible snails (IIa and Ib) may be attributed to the effect of the interaction between age and genetics on compatibility patterns. This was represented by a longer PPP in the susceptible individuals in subgroup IIa than in snails of the aforementioned adult susceptible subgroup.

In the current study, some individuals of subgroups $\mathrm{IIa}$ and $\mathrm{Ib}$ displayed a PPP of 49 days. The delay in parasite development in these snails indicates their lower susceptibility to infection. A comparison between the young resistant (IIa) subgroup and adult susceptible (Ib) subgroup revealed that 11 snails shed for the first time on the 49th day in the former group, but only seven in the latter. However, this difference was not statistically significant, indicating that both age and compatibility pattern are important in determining the outcome of infection.

Richards (1984) stated that genetic factors determining B. glabrata juvenile nonsusceptibility operate throughout the snail's life, masking the presence of the factors for adult susceptibility and, thus, unfortunately complicating studies on the influence of age on snail susceptibility.

The highest IR in the present study was exhibited by the snails belonging to the young susceptible subgroup Ia. In total, $92 \%$ of subgroup Ia (young susceptible), $74 \%$ of subgroup Ib (adult susceptible) and 37\% of subgroup IIa (young resistant) were susceptible. All snails in subgroup IIb (adult resistant) were resistant. It should be noted that even the snails that died during the course of the experiment were included in the statistical analysis; these snails were examined for developing sporocysts.

Although our experiment was carried out on snails resulting from self-reproduction, some resistant snails were obtained in the progeny of susceptible individuals, indicating the dominance of the resistance character in B. alexandrina. In their studies, both Shoukry et al. (1997) and El Naga et al. (2010) observed the appearance of resistant snails originating from cross of susceptible parents. A probable explanation for the resistant members obtained in the susceptible subgroups is that, although resistance alleles are sometimes not expressed in the snail phenotype, they can accumulate through generations to produce a resistant phenotype that appears in later progeny. That is, the parents of these resistant snails harboured unexpressed resistance genes, which subsequently accumulated among successive generations (El Naga et al. 2010). Similarly, the resistance character in $B$. glabrata snails is inherited in a dominant manner (Richards \& Merritt 1972, Lewis et al. 2002). Abdel-Hamid et al. (2006) and El-Nassery et al. (2013) found that both susceptibility and resistance in B. alexandrina are hereditary characters and are genetically controlled.

In contrary to Lewis et al. (2002), who found that susceptible $B$. glabrata parents did not give rise to any resistant progeny, susceptible subgroups in the current study resulted in $8-26 \%$ resistant individuals in the two age groups. This could be explained by the proposal of El Naga et al. (2010) that a susceptible population of $B$. alexandrina may contain more resistance alleles than $B$. glabrata, thus accounting for the appearance of resistant progeny originating from completely susceptible parents. Although the two susceptible subgroups contained resistant snails, the significant difference noted between them suggests that the resistant alleles obtained from $F_{1}$ parents were potentiated by the impact of age, resulting in the appearance of more resistant individuals in the adult susceptible subgroup (Ib).

In the current work, no susceptible members were obtained in the adult resistant subgroup (IIb). This result was also observed in other studies using different species (Lewis et al. 2002, Rosa et al. 2005, El Naga et al. 2010). However, 37 susceptible members were recorded in our young resistant subgroup (IIa), which reinforces our assumption on the effect of the age of B. alexandrina on snail compatibility pattern. The appearance of susceptible individuals in the young resistant subgroup could also be explained by its weaker internal defence when compared to the adult resistant subgroup. This was proven by the significant difference noted in SOD1 enzyme activity between resistant snails in the young and adult resistant subgroups, at $0.68 \pm 0.04$ and $0.90 \pm 0.07$ $\mathrm{U} / \mathrm{g}$ tissues, respectively.

Anderson et al. (1982) attributed the lower IRs of adult snails compared to younger snails to a number of different factors. First, older snails possess physical barriers to penetration imposed by their tough thickened body covering. Additionally, they produce greater quantities of mucus, which replete with chemicals that confuse searching miracidia. Moreover, adults possess a higher phagocytic capacity. Older snails also move faster and are thus more difficult to locate by miracidia. Furthermore, egg-laying capacity could be among the factors causing more resistance in adult snails, wherein the snail expends all its energy on reproduction, as stated by Richards (1977).

Our main goal was to ascertain whether resistant alleles transmitted from susceptible parent snails to their young progeny are more functional at the adult stage and our results suggest that they are. We propose that resistance alleles in the susceptible population may become more functional through the snail aging process, which is responsible for the lower susceptibility in adult B. alexandrina snails.

The highest susceptibility in the young susceptible subgroup was also evidenced by the highest TCP among the four studied subgroups, at 151,002. This was followed by the adult susceptible subgroup, which produced 41,732 cercariae over the three weeks of shedding. The young resistant subgroup ranked next, with 9,877 over the shedding weeks. According to the Frandsen classification, the three subgroups can be categorised in classes 4, 2 and 1 (well compatible, poorly compatible and not very compatible, respectively). Regarding the adult resistant subgroup, no cercariae were produced at all, placing this subgroup in Frandsen class 0 or resistant snails (Frandsen 1979).

The recorded MRs in the present study were $47 \%$, $35 \%, 27 \%$ and $14 \%$ in subgroups Ia, Ib, IIa and IIb, respectively and were directly proportional to the IRs in the different subgroups. The higher MRs noted in the susceptible compared to the resistant groups could be explained by the devastating effects of $S$. mansoni on 
snail health. S. mansoni is considered a parasite that exerts a selective pressure on the susceptible population. During its development, S. mansoni sporocysts invade Biomphalaria's digestive gland and the adjacent gonads, leading to destruction of these organs (Lemos \& Andrade 2001). Thus, infection becomes an element of natural selection, which is highly negative for infected snails (Rosa et al. 2006). Moreover, the disturbance in metallic ion concentrations due to trematode infection is considered another cause of mortality in parasitised snails (Mostafa \& Dajem 2010). Furthermore, the exposure of susceptible snails to a high dose of infection (8-10 miracidia) per snail at the same time may explain the higher mortality recorded in the laboratory, as the majority of these miracidia are thought to develop without much restraint. In contrast, under natural conditions, the snail is not likely to be exposed to such a high number of miracidia at a given time (Corrêa \& Paraense 1971).

The MRs recorded in the two resistant subgroups were $35 \%$ and $14 \%$, subgroups IIa (young resistant) and IIb (adult resistant), respectively. The mortality of the resistant snails can be attributed to a high concentration of the SOD1 enzyme, which produces $\mathrm{H}_{2} \mathrm{O}_{2}$, a highly ROS. Although these reactive species are beneficial for combating the invading parasite, they also seriously damage biological membranes in the host tissue, the so-called "cost of resistance" (Bender et al. 2007, Bonner et al. 2012); hence, ROS are considered a double-edged sword (Beckman \& Ames 1998). Mangal et al. (2010) stated that exposure alone of $B$. alexandrina snails to $S$. mansoni miracidia has a negative impact on snail survival rates.

In the present work, we functionally investigated the activity of the SOD1 enzyme in a whole-snail soft tissue homogenate at two weeks after exposure to infection. For the control noninfected snails, the results were 0.26 \pm 0.04 and $0.30 \pm 0.03 \mathrm{U} / \mathrm{g}$ of SOD1 activity in the noninfected young and adult groups, respectively. No significant difference was calculated between the two control groups. Cytosolic SOD1 is present during the course of the snail lifetime to protect cells against damage by the free radicals that are generated due to normal metabolism (Bender et al. 2005).

Regarding the results of the experimental subgroups in the current study, the combined effects of both age and compatibility pattern resulted in the highest SOD1 activity in the adult resistant subgroup, with a mean of $0.90 \pm$ $0.07 \mathrm{U} / \mathrm{g}$ tissue. In contrast, the lowest enzyme activity was found in the susceptible snails of the young susceptible subgroup, at $0.32 \pm 0.03 \mathrm{U} / \mathrm{g}$ tissue. Furthermore, as shown in Table VII, the SOD1 activities were higher in the resistant individuals of the studied subgroups than in the corresponding susceptible individuals. This indicates the importance of this enzyme in determining a snail's compatibility status. Our results of higher SOD1 activity levels in resistant vs. susceptible snails are in agreement with Hahn et al. (2001), Goodall et al. (2004), Mahmoud and Rizk (2004), Bender et al. (2005) and Bayne (2009), who reported an increased number of haemocytes generating superoxide in S. mansoni resistant snails. The resulting free radicals were efficient for encapsulating or eliminating the parasite in resistant snails, but failed in the case of susceptible snails (Mahmoud \& Rizk 2004).
It is worth mentioning that studies on the genes of a resistant $B$. glabrata strain have revealed that polymorphisms in the gene encoding cytosolic SOD1 are associated with susceptibility/resistance; such results reinforce the role of SOD1 in schistosome resistance (Goodall et al. 2004, 2006, Bender et al. 2007).

The results of the present work showed that the age of B. alexandrina snails affects SOD1 activity levels. Significant differences in SOD1 activity levels between young and adult snails obtained from the same $\left(\mathrm{F}_{1}\right)$ parent were observed, with a higher activity at the adult stage. Goodall et al. (2006) reported that Biomphalaria SOD1 is encoded by three alleles and one was found to be significantly associated with resistance. Furthermore, some alleles controlling compatibility were found to be affected by snail age (Richards 1977, Richards \& Shade, Richards et al. 1992). Within this context, it would be interesting to assess whether the genes encoding SOD1 are among the other genes that are modified by snail age.

In summary, the significant differences in all parasitological and biochemical parameters between young and adult snails in the same group were attributed to the age effect, which made resistance alleles more functional in adults, with higher SOD1 enzyme activity. Moreover, the complex interaction between age, genetic background and IDS between the susceptible and resistant subgroups results in great variability in compatibility patterns. This interaction led to the appearance of the highest significant difference between the young susceptible (Ia) and adult resistant (IIb) subgroups.

The results presented herein can have potential epidaemiological implications in Biomphalaria control. By determining the age at which a snail is most susceptible to $S$. mansoni infection, the optimal timing for the application of molluscicides could be identified. This in turn would increase the efficacy of the applied method, potentiating schistosomiasis control. Moreover, identification of the most resistant snails is important for use in later biological snail control, after studying the compatibility of successive generations.

Investigations of genes encoding enzymes involved in the respiratory burst are recommended. In particular, the genes responsible for the production of $\mathrm{H}_{2} \mathrm{O}_{2}$ should be targeted as potential candidates for genetic loci causally related to the susceptibility/resistance of $B$. alexandrina to S. mansoni at different snail ages.

\section{REFERENCES}

Abdel-Hamid A-HZ, Rawi SM, Arafa AF 2006. Identification of genetic marker associated with the resistance to Schistosoma mansoni infection using random amplified polymorphic DNA analysis. Mem Inst Oswaldo Cruz 101: 863-868.

Anderson RM, Mercer JG, Wilson RA, Carter NP 1982. Transmission of Schistosoma mansoni from man to snail: experimental studies of miracidial survival and infectivity in relation to larval age, water temperature, host size and host age. Parasitology 85: 339-360.

Bayne CJ 2009. Successful parasitism of vector snail Biomphalaria glabrata by the human blood fluke (trematode) Schistosoma mansoni: a 2009 assessment. Mol Biochem Parasitol 165: 8-18.

Beckman KB, Ames BN 1998. The free radical theory of aging matures. Physiol Rev 78: 547-581. 
Bender RC, Broderick EJ, Goodall CP, Bayne CJ 2005. Respiratory burst of Biomphalaria glabrata hemocytes: Schistosoma manso$n i$-resistant snails produce more extracellular $\mathrm{H}_{2} \mathrm{O}_{2}$ than susceptible snails. J Parasitol 91: 275-279.

Bender RC, Goodall CP, Blouin MS, Bayne CJ 2007. Variation in expression of Biomphalaria glabrata SOD1: a potential controlling factor in susceptibility/resistance to Schistosoma mansoni. Dev Comp Immunol 31: 874-878.

Bonner KM, Bayne CJ, Larson MK, Blouin MS 2012. Effects of Cu/ $\mathrm{Zn}$ superoxide dismutase (SOD1) genotype and genetic background on growth, reproduction and defense in Biomphalaria glabrata. PLoS Negl Trop Dis 6: e1701.

Chu KY, Dawood IK 1970. Cercarial production from Biomphalaria alexandrina infected with Schistosoma mansoni. Bull World Health Organ 42: 569-574.

Coelho PMZ, Carvalho OS, Andrade ZA, Martins-Sousa RL, Rosa FM, Barbosa L, Pereira CAJ, Caldeira RL, Jannotti-Passos LK, Godard ALB, Moreira LA, Oliveira GC, Franco GR, Teles HMS, Negrão-Corrêa D 2004. Biomphalaria tenagophila/Schistosoma mansoni interaction: premises for a new approach to biological control of schistosomiasis. Mem Inst Oswaldo Cruz 99 (Suppl. I): $109-111$

Corrêa LR, Paraense WL 1971. Susceptibility of Biomphalaria amazonica to infection with two strains of Schistosoma mansoni. Rev Inst Med Trop Sao Paulo 13: 387-390.

de Jong-Brink M 1995. How schistosomes profit from the stress responses they elicit in their hosts. Adv Parasitol 35: 177-256.

DeJong RJ, Morgan JA, Paraense WL, Pointier JP, Amarista M, AyehKumi PF, Babiker A, Barbosa CS, Brémond P, Canese AP, de Souza CP, Dominguez C, File S, Gutierrez A, Incani RN, Kawano T, Kazibwe F, Kpikpi J, Lwambo NJ, Mimpfoundi R, Njiokou F, Poda JN, Sene M, Velásquez LE, Yong M, Adema CM, Hofkin BV, Mkoji GM, Loker ES 2001. Evolutionary relationships and biogeography of Biomphalaria (Gastropoda: Planorbidae) with implications regarding its role as host of the human blood fluke, Schistosoma mansoni. Mol Biol Evol 18: 2225-2239.

Dettman CD, Higgins-Opitz SB, Saikoolal A 1989. Enhanced efficacy of the paddling method for Schistosoma infection of rodents by a four-step pre-soaking procedure. Parasitol Res 76: 183-184.

El Naga IF, El-Nassery SMF, Allam SR, Shaat EA, Mady RFM 2011. Biomphalaria species in Alexandria water channels. Parasitol Int 60: $247-254$.

El Naga IF, Radwan EH 2012. Defense response of susceptible and resistant Biomphalaria alexandrina snails against Schistosoma mansoni infection. Rev Biol Trop 60: 1195-1204.

El Naga IFA, Eissa MM, Mossallam SF, El-Halim SIA 2010. Inheritance of Schistosoma mansoni infection incompatibility in Biomphalaria alexandrina snails. Mem Inst Oswaldo Cruz 105: 149-154.

El-Nassery SM, Abou-El-Naga IF, Allam SR, Shaat EA, Mady RF 2013. Genetic variation between Biomphalaria alexandrina snails susceptible and resistant to Schistosoma mansoni infection. Biomed Res Int 2013: ID 160320.

Eveland LK, Haseeb MA 2011. Laboratory rearing of Biomphalaria glabrata snails and maintenance of larval schistosomes in vivo and in vitro. In Biomphalaria snails and larval trematodes, Springer, New York, p. 33-55.

Frandsen F 1979. Studies of the relationship between Schistosoma and their intermediate hosts. III. The genus Biomphalaria and Schistosoma mansoni from Egypt, Kenya, Sudan, Uganda, West Indies (St. Lucia) and Zaire (two different strains: Katanga and Kinshasa). J Helminthol 53: 321-348.

Goodall CP, Bender RC, Broderick EJ, Bayne CJ 2004. Constitutive differences in $\mathrm{Cu} / \mathrm{Zn}$ superoxide dismutase mRNA levels and ac- tivity in hemocytes of Biomphalaria glabrata (Mollusca) that are either susceptible or resistant to Schistosoma mansoni (Trematoda). Mol Biochem Parasitol 137: 321-328.

Goodall CP, Bender RC, Brooks JK, Bayne CJ 2006. Biomphalaria glabrata cytosolic copper/zinc superoxide dismutase (SOD1) gene: association of SOD1 alleles with resistance/susceptibility to Schistosoma mansoni. Mol Biochem Parasitol 147: 207-210.

Hahn UK, Bender RC, Bayne CJ 2001. Killing of Schistosoma mansoni sporocysts by hemocytes from resistant Biomphalaria glabrata: role of reactive oxygen species. J Parasitol 8: 292-299.

Haroun NH 1996. Differences in susceptibility of Biomphalaria alexandrina to Schistosoma mansoni from Giza and Dakahlia Governorates, Egypt. J Egypt Soc Parasitol 26: 327-335.

Hotez PJ, Savioli L, Fenwick A 2012. Neglected tropical diseases of the Middle East and North Africa: review of their prevalence, distribution and opportunities for control. PLos Negl Trop Dis 6: e1475.

Hubendick B 1958. A possible method of schistosome-vector control by competition between resistant and susceptible strains. Bull World Health Organ 8: 1113-1116.

Ittiprasert W, Miller A, Myers J, Nene V, El-Sayed NM, Knight M 2010. Identification of immediate response genes dominantly expressed in juvenile resistant and susceptible Biomphalaria glabrata snails upon exposure to Schistosoma mansoni. Mol Biochem Parasitol 169: 27-39.

King CH, Dickman K, Tisch DJ 2005. Reassessment of the cost of chronic helminthic infection: a meta-analysis of disability-related outcomes in endemic schistosomiasis. Lancet 365: 1561-1569.

Kirkpatrick LA, Feeney BC 2013. A simple guide to IBM SPSS statistics for version 20.0, Belmont, Wadsworth, Cengage Learning.

Knight M, Arican-Goktas HD, Ittiprasert W, Odoemelam EC, Miller AN, Bridger JM 2014. Schistosomes and snails: a molecular encounter. Front Genet 5: 230.

Kotz S, Balakrishnan N, Read CB, Vidakovic B 2006. Encyclopedia of statistical sciences, 2nd ed., Hoboken, John Wiley \& Sons, $1516 \mathrm{pp}$.

Lemos QT, Andrade ZA 2001. Sequential histological changes in Biomphalaria glabrata during the course of Schistosoma mansoni infection. Mem Inst Oswaldo Cruz 96: 719-721.

Lewis FA, Patterson CN, Gizywarz C 2002. Parasite susceptibility phenotypes of $\mathrm{F}_{1}$ Biomphalaria glabrata progeny derived from interbreeding of Schistosoma mansoni resistant and susceptible snails. Parasitol Res 89: 98-101.

Loker ES 2010. Gastropod immunobiology. Adv Exp Med Biol 708: $17-43$.

Mahmoud AH, Rizk MZ 2004. Free radical scavengers in susceptible/ resistant Biomphalaria alexandrina snails before and after infection. Comp Biochem Physiol C Toxicol Pharmacol 138: 523-530.

Mangal TD, Paterson S, Fenton A 2010. Effects of snail density on growth, reproduction and survival of Biomphalaria alexandrina exposed to Schistosoma mansoni. J Parasitol Res 2010: 186792.

Marques DP, Rosa FM, Maciel E, Negrão-Corrêa D, Teles HM, Caldeira RL, Jannotti-Passos LK, Coelho PM 2014. Reduced susceptibility of a Biomphalaria tenagophila population to Schistosoma mansoni after introducing the resistant Taim/RS strain of B. tenagophila into Herivelton Martins Stream. PLoS ONE 9: e99573.

Morgan JA, Dejong RJ, Snyder SD, Mkoji GM, Loker ES 2001. Schistosoma mansoni and Biomphalaria: past history and future trends. Parasitol 123: 211-228.

Mostafa OM, El-Dafrawy SM 2011. Susceptibility of Biomphalaria spp to infection with Schistosoma mansoni in sympatric and allopatric combinations with observations on the genetic variability between snails. Vet Parasitol 180: 226-231. 
Mostafa OMS, Dajem SMB 2010. Effects of Schistosoma mansoni experimental infection on some inorganic elements in the snail host Biomphalaria alexandrina. J Egypt Soc Parasitol 40: 197-204.

Negrão-Corrêa D, Pereira CAJ, Rosa FM, Martins-Souza RL, Andrade ZA, Coelho PMZ 2007. Molluscan response to parasite: $B i$ omphalaria and Schistosoma mansoni interaction. Invertebrate Surviv J 4: 101-111.

Newton WL 1952. The inheritance of susceptibility to infection with Schistosoma mansoni in Australorbis glabratus. Exp Parasitol 2: 525-541.

Niemann GM, Lewis FA 1990. Schistosoma mansoni: influence of Biomphalaria glabrata size on susceptibility to infection and resultant cercarial production. Exp Parasitol 70: 286-292.

Njiokou F, Teukeng E, Bilong CF, Njiné T, Ekobo AS 2004. Experimental study of the compatibility between Schistosoma haematobium and two species of Bulinus in Cameroon. Bull Soc Pathol Exot 97: 43-46.

Oliveira AL, da Silva D, Manzano BC, Abdel-Hamid AZ, Marcelino MY, Zanotti-Magalhães EM, Magalhães LA, Ribeiro-Paes JT 2010. Genetic differences between strains of Biomphalaria glabrata (Planorbidae) that are susceptible and unsusceptible to schistosomiasis. Genet Mol Res 9: 1450-1459.

Richards CS 1975. Genetic factors in susceptibility of Biomphalaria glabrata for different strains of Schistosoma mansoni. Parasitology 70: 231-241.

Richards CS 1977. Schistosoma mansoni: susceptibility reversal with age in the snail host in Biomphalaria glabrata. Exp Parasitol 42: 165-168

Richards CS 1984. Influence of snail age on genetic variations in susceptibility of Biomphalaria glabrata for infection with Schistosoma mansoni. Malacologia 25: 493-502.

Richards CS, Knight M, Lewis FA 1992. Genetic of Biomphalaria glabrata and its effect on the outcome of Schistosoma mansoni infection. Parasitol Today 8: 171-174.

Richards CS, Merritt JR 1972. Genetic factors in the susceptibility of juvenile Biomphalaria glabrata to Schistosoma mansoni infection. Am J Trop Med Hyg 21: 425-434.

Richards CS, Shade PC 1987. The genetic variation of compatibility in Biomphalaria glabrata and Schistosoma mansoni. J Parasitol 73: $1146-1151$

Rosa FM, Godard ALB, Azevedo V, Coelho PMZ 2005. Biomphalaria tenagophila: dominant character of the resistance to Schistosoma mansoni in descendants of crossbreeding between resistant
(Taim, RS) and susceptible (Joinville, SC) strains. Mem Inst Oswaldo Cruz 100: 19-23.

Rosa FM, Godard ALB, Negrão-Correa D, Rodrigues HA, Carvalho OS, Caldeira RL, Teles HMS, Maciel E, Jannotti-Passos LK, Coelho PMZ 2006. Biomphalaria tenagophila: dynamics of populations of resistant and susceptible strains to Schistosoma mansoni, with or without pressure of the parasite. Mem Inst Oswaldo Cruz 101 (Suppl. I): 247-251.

Sandland GJ, Foster AV, Zavodna M, Minchella DJ 2007. Interplay between host genetic variation and parasite transmission in the Biomphalaria glabrata-Schistosoma mansoni system. Parasitol Res 101: 1083-1089.

Sapan CV, Lundblad RL, Price NC 1999. Colorimetric protein assay techniques. Biotechnol Appl Biochem 29: 99-108.

Shoukry NM, Elassal FM, Soliman GN, Mansour NS 1997. Susceptibility of three successive snail generations from positive and negative laboratory bred Biomphalaria alexandrina from different localities in Egypt to infection with Schistosoma mansoni from Giza. J Egypt Soc Parasitol 27: 317-329.

Spada RGM, da Silva D, Abdel-Hamid A-Z, Sobral-Hamaguchi SS, Zuim NRB, Zanotti-Magalhães EM, Magalhães LA, RibeiroPaes JT 2002. Genetic markers between Biomphalaria glabrata snails susceptible and resistant to Schistosoma mansoni infection. Mem Inst Oswaldo Cruz 97 (Suppl. I): 53-58.

Steinmann P, Keiser J, Bos R, Tanner M, Utzinger J 2006. Schistosomiasis and water resources development: systematic review, meta-analysis and estimates of people at risk. Lancet Infect Dis 6: 411-425.

Todd MJ, Gomez J 2001. Enzyme kinetics determined using calorimetry: a general assay for enzyme activity? Anal Biochem 296: 179-187.

Townson H, Nathan MB, Zaim M, Guillet P, Manga L, Bos R, Kindhauser M 2005. Exploiting the potential of vector control for disease prevention. Bull World Health Organ 83: 942-947.

WHO - World Health Organization 2014. Schistosomiasis. Available from: who.int/mediacentre/factsheets/fs115/en/.

Yousif F, Ibrahim A, El-Bardicy SN 1998. Compatibility of Biomphalaria alexandrina, Biomphalaria glabrata and a hybrid of both to seven strains of Schistosoma mansoni from Egypt. $J$ Egypt Soc Parasitol 28: 863-881.

Zanotti-Magalhães EM, Magalhães LA, Carcalho JF 1997. Relationship between pathogenicity of Schistosoma mansoni in mice and the susceptibility of the vector mollusk. IV. Infectiousness of miracidia. Rev Saude Publica 31: 488-494. 